\title{
Personal and familial predictors of depressive feelings in people with orthopedic disability
}

\begin{abstract}
BACKGROUND
People with orthopedic disability experience limitations in physical ability, which can cause psychological problems such as depressive feelings. This paper investigates the role of family environment, caregiver characteristics, and personal resources in the acceptance of disability and depressive feelings of persons with orthopedic disability.
\end{abstract}

\section{PARTICIPANTS AND PROCEDURE}

Data were collected from 161 Turkish people with orthopedic disability (mean age $=35.60$ years, $S D=10.18$ ) and their family caregivers (e.g., parent, spouse). The participants with disability completed scales for functional independence, acceptance of disability, family environment, locus of control, learned resourcefulness, and depression. The family caregivers completed measures of social support, their own depression, burden of caregiving, and acceptance-rejection of their care recipient.

\section{RESULTS}

Analyses via multivariate statistics and SEM showed that depressive feelings of individuals with orthopedic disabil-

\begin{abstract}
ity and their acceptance of the disability were predicted by multiple factors, including the affected persons' learned resourcefulness and locus of control, family environment, and interactions with their family caregiver, but not by their functional independence.
\end{abstract}

\section{CONCLUSIONS}

Overall, a supportive family environment and acceptance of disability appear to lower the risk of having depression for individuals with orthopedic disability. Family caregivers' attitudes towards their care recipients were related to the family environment, and feelings of burden appeared to impair the affected individuals' acceptance of their condition.

\section{KEY WORDS}

orthopedic disability; depression; acceptance of disability; family caregiver; social support

ORGANIZATION - 1: Department of Psychology, Indiana University-Purdue University Indianapolis, IN, United States .

2: Department of Psychology, Koç University, Istanbul, Turkey · 3: Kadir Has University, Istanbul, Turkey

aUthors' Contributions - A: Study design - B: Data collection - C: Statistical analysis - D: Data interpretation .

E: Manuscript preparation · F: Literature search · G: Funds collection

CORRESPONDING AUTHOR - Ekin Secinti, Department of Psychology, Indiana University-Purdue University Indianapolis,

IN, United States, e-mail: esecinti@iupui.edu

to Cite this ARTicle - Secinti, E., Selcuk, B., \& Harma, M. (2017). Personal and familial predictors of depressive

feelings in people with orthopedic disability. Health Psychology Report, 5(3), 227-239. doi: https://doi.org/10.5114/

hpr.2017.65206

RECEIVED 09.08.2016 · REVIEWED 08.09.2016 · ACCEPTED 01.10.2016 · PUBLISHED 25.01.2017 


\section{BACKGROUND}

Orthopedic disability is a permanent disorder characterized by functional limitations in movement and posture as a result of congenital anomaly, disease, trauma, and other causes such as infection (Pierangelo \& Giuliani, 2007). Whether congenital or acquired (traumatically or gradually), orthopedic disability exerts a major impact on the affected individuals and their families (Keany \& Gluekauf, 1993). Limitations in physical abil-

Ekin Secinti, Bilge Selcuk, Mehmet Harma ity not only adversely influence the mobility of people with orthopedic disability, but can also cause social and psychological problems such as depression (Crichlow, Andres, Morrison, Haley, \& Vrahas, 2006; Post \& van Leeuwen, 2012). In order to alleviate these problems, it is important to identify factors that contribute to the depressive feelings they may experience.

People with orthopedic disability can often encounter problems such as pain and a progressive decline of energy and muscle use, and may need assistance for various daily activities such as eating, dressing, transfer, and bowel and bladder care (Robinson-Whelen \& Rintala, 2003; Weitzenkamp, Gerhart, Charlifue, \& Whiteneck, 1997). Therefore, there is usually a family caregiver who lives with people with orthopedic disabilities and interacts with them on a daily basis (Dreer, Elliott, Shewchuk, Berry, \& Rivera, 2007). Due to such a living arrangement that requires continual interaction between the individual with disability and his/her relative, the characteristics and functioning of the caregiving family member might be among the factors affecting the emotional well-being of individuals with disabilities. Yet research on this topic is limited. In this study, we aimed to examine the adaptation of individuals with orthopedic disabilities to their condition of disability, the level of depressive feelings they experience, and the role of family environment, family caregiver characteristics, and personal attitudes in their adaptation to disability and related depressive feelings. We conducted the study in Turkey, where orthopedic disability is a common form of impairment affecting $1.23 \%$ of the population (Turkish Statistical Institute, 2010), and where inadequate infrastructure and limited health care and social services make independent living almost impossible for people with disabilities.

\section{PERSONAL FACTORS ASSOCIATED WITH DEPRESSION IN PEOPLE WITH DISABILITY}

Depression is recognized as the most common and disabling condition secondary to major functional impairments such as spinal cord injury (Craig, Tran, \& Middleton, 2009), amputation (Singh et al., 2009), spina bifida (Bellin et al., 2010), and polio (Kahan, Mitchell, Kemp, \& Adkins, 2006). Depres- sion is estimated to afflict $20 \%$ to $40 \%$ of adults with various physical disabilities, much higher than the age-matched general population without disability, which tends to be below $10 \%$ (Post \& van Leeuwen, 2012; Singh et al., 2009). Also, suicidal ideation is more prevalent in individuals with disability, with suicide attempt rates nearly five times the general population rates (DeVivo, Black, Richards, \& Stover, 1991; Russell, Turner, \& Joiner, 2009).

A major factor leading to depressive feelings among people with disabilities is the barriers they face on a daily basis. The physical barriers such as mobility problems and social barriers such as negative attitudes towards individuals with disability and discrimination in employment produce significant distress, exacerbating the risk of depression. People with disabilities have a lower quality of life (Post \& van Leeuwen, 2012), and their satisfaction in life is further lowered with depression (Budh \& Osteraker, 2007).

Researchers have tried to elucidate the factors which increase or alleviate the level of depression in people with disability. Locus of control as an inherent psychological factor is significantly related to depression (Benassi, Sweeney, \& Dufour, 1988). Specifically, depression is associated with an external locus of control; that is, individuals who believe that luck, fate or a supreme being is responsible for their condition, and who think that they have limited control over their lives (Rotter, 1966), have greater emotional difficulty (Pelletier, Alfano, \& Fink, 1994). For people with orthopedic disability, the extent to which they believe they are responsible for their condition also affects the extent to which these individuals evaluate the outcomes as contingent on their own behavior (Waldron et al., 2010). In other words, acknowledging a role in the control over one's own health is a predictor of adjustment to disability. To this end, spinal cord injury patients with an internal locus of control have been found to demonstrate better psychological adjustment to disability and greater life satisfaction, whereas those with an external locus of control have higher levels of depression (see van Leeuwen, Kraaijeveld, Lindeman, \& Post, 2012, for review). Similarly, in hemodialysis patients, an external locus of control was found to be predictive of high levels of depression (Baydogan \& Dag, 2008).

Another factor that may alleviate depressive feelings is learned resourcefulness. As an effective coping mechanism, learned resourcefulness includes an acquired set of cognitions, behaviors and self-control skills that are implemented while dealing with stressful events (Rosenbaum, 1990). High resourcefulness is significantly associated with lower levels of depression for patients with breast cancer (Huang et al., 2010), epilepsy (Rosenbaum \& Palmon, 1984) and hemodialysis (Baydogan \& Dag, 2008). The extant literature has not focused on learned resourcefulness in people with orthopedic disability, but resourceful- 
ness interventions improved psychological adjustment among people with chronic illnesses (Drummond-Young, LeGris, Browne, Pallister, \& Roberts, 1995), suggesting that resourcefulness is an important resource for reducing depressive feelings in this population as well.

An important step on the road to reducing depressive feelings in people with disability is the individual's adjustment to and acceptance of disability (Li \& Moore, 1998). As a continuous transition, adjustment to disability is an iterative process whereby one learns to consolidate different aspects of one's position in life (Kendall \& Buys, 1998). Acceptance of disability is a way that helps this adaptation. In order to accept the disability, the person has to take his/ her own values into consideration and not let his/her actual or perceived losses stemming from the disability to negatively affect his/her perception of existing abilities (Keany \& Glueckauf, 1993). Once achieved, acceptance of disability facilitates independent living (Green, Pratt, \& Grigsby, 1984) and employment (Melamed, Groswasser, \& Stem, 1992). It is positively correlated with adjustment (Elliott, Uswatte, Lewis, \& Palmatier, 2000) and social integration in the community. Those who accept their disability have greater satisfaction with life (Snead \& Davis, 2002); they demonstrate a greater sense of empowerment, fewer depressive symptoms, and are less preoccupied with the negative impacts of disability such as experiencing pressure, pain, and muscle spasms (Attawong \& Kovindha, 2005; Elliott, 1999). So, being able to accept one's predicament without perceiving disability as a devaluing factor appears to be an essential task to master. Acceptance of disability does not demonstrate a consistent relationship with disability severity (Jiao, Heyne, \& Lam, 2012; Woodrich \& Patterson, 1983), but is related to psychosocial variables such as higher self-esteem (Li \& Moore, 1998), positive orientation towards problem solving (Elliott, 1999), a greater sense of goal orientation (Elliott et al., 2000), and an internal locus of control (van Leeuwen et al., 2012). Yet there is limited literature on investigating the role of the family in the individual's acceptance of disability.

\section{FAMILIAL FACTORS ASSOCIATED WITH DEPRESSIVE FEELINGS IN PEOPLE WITH DISABILITY}

When living with a family member with orthopedic disability, the family, as a system, experiences increased distress, which may have an adverse impact on their functioning in a negative way (Ylven, Bjorck-Akesson, \& Granlund, 2006). However, the family is also an important resource helping individuals accept their disability and cope with their problems. The love and affection provided by a pos- itive family environment is necessary for a healthy self-image, to achieve successful adjustment to disability, and to cope with adversities that have the potential to cause depression. Social support received from the family is particularly important for individuals with orthopedic disability. A review paper (Müller, Peter, Cieza, \& Geyh, 2012) revealed that social support is significantly linked with life satisfaction, quality of life and well-being of individuals with spinal cord injury. Social support might provide the resources that promote well-being (Kemp \& Krause, 1999) and serve as a protective factor against helplessness (Elfstrom, Kreuter, Ryden, Persson, \& Sullivan, 2002), pessimism, depression, and suicidal intent (Beedie \& Kennedy, 2002; Jiao et al., 2012; Kishi $\&$ Robinson, 1996). Higher social support from family and friends has also been linked with better physical and mental health, and improved outcomes following orthopedic disability, including acceptance of disability (Jiao et al., 2012; Rintala, Robinson-Whelen, \& Matamoros, 2005), higher quality of life (Post \& van Leeuwen, 2012), a decreased number of hospitalizations, and decreased mortality (Krause, Sternberg, Lottes, \& Maides, 1997).

These findings indicate that the family includes various features which, when functioning well, may reduce the depressive feelings of individuals with disability. However, family caregivers of individuals with orthopedic disability also undergo various difficulties themselves; they experience financial strain (Sav et al., 2013), health problems resulting from caregiving such as pain and disruptions in the functioning of the cardiovascular and immune systems (Donelan et al., 2002; Vitaliano, Zhang, \& Scanlan, 2003), elevated levels of distress (Chan, Lee, \& LiehMak, 2000), anxiety, and a lower quality of life (Elliott $\&$ Berry, 2009). Family caregivers who report a greater caregiving burden have a greater tendency to feel decreased life satisfaction and high levels of depression (Dreer, Elliott, Shewchuk, Berry, \& Rivera, 2007; Unalan et al., 2001). They are also more likely to have negative attitudes towards their family member with disability (Elliott \& Pezent, 2008), which disrupts the positive family environment. Social support is also a protective factor for family caregivers (Cavallo, Feldman, Swaine, \& Meshefedjian, 2008; Williams, Wang, \& Kitchen, 2016). When feeling supported by their family and friends, caregivers have better psychological well-being (DeLongis \& Holzman, 2005), lower depression, and they hold more positive attitudes towards their family member with disability (Moroni, Colangelo, Gallì, \& Bertolotti, 2007; Oh \& Lee, 2009).

Overall, studies have reported significant negative relations between depressive feelings and a positive family environment for individuals with orthopedic disability, but characteristics of family caregivers and the personal psychological resources of the individual with disability have rarely been studied together
Depressive feelings in orthopedic disability 
in this literature. In the present study, we focused on burden, social support and depression experienced by the family caregiver, the caregiver's acceptance-rejection towards the family member with disability, and the personal psychological resources of the individual with disability (learned resourcefulness, locus of control), and explored how these multiple factors are related to the acceptance of disability and depressive feelings.

Ekin Secinti, Bilge Selcuk, Mehmet Harma

\section{PARTICIPANTS}

The participants were 161 individuals with orthopedic disability living in Turkey and their caregiving family member living with the individual with orthopedic disability (see Table 1 for sociodemographic and clinical information). In this study, family caregiver is defined as the person who was primarily responsible for the immediate care of the persons with orthopedic disability.

The participants were residing in 12 different cities located in five districts of Turkey. Of the participants with orthopedic disability, the majority were wheelchair users. On average, participants with orthopedic disability were $35.60(S D=10.18)$ years old. Over half of the individuals with orthopedic disability were single, had not graduated from high school, and were unemployed. Their family caregivers were mostly their mothers or spouses. On average, the family caregivers were $44.07(S D=14.79)$ years old. Of the family caregivers, the majority were female, had not graduated from high school, and were unemployed.

\section{MEASURES}

The participants with orthopedic disability completed questionnaires that measured their own functional independence, acceptance of disability, familial support, family functioning, locus of control, learned resourcefulness, and depression. The family caregivers completed questionnaires for the assessment of support they perceived to receive from family and friends, their own depression, burden of caregiving, and acceptance-rejection of their family member with orthopedic disability.

\section{Measures for the participants with disability}

Background information. We administered a form to the participants with orthopedic disability to obtain descriptive information about them and their families (e.g., age, sex, education, income, marital status). The form also included questions about the orthopedic disability (e.g., form, onset, cause).
Functional independence. We used the Spinal Cord Independence Measure (SCIM-III; Fekete et al., 2013) to assess the level of functionality of the participant with disability. The SCIM-III included items that tapped mobility (9 items; e.g., I need an electric wheelchair or partial assistance to operate a manual wheelchair), selfcare (4 items), and sphincter management (1 item; e.g., I use the toilet independently without assistance or a device). Three items on respiration and sphincter management were omitted, as they were not applicable to all participants. Items were rated on different scales ranging from 2 to 9 (see Fekete et al., 2013 for grading), with higher scores indicating increased functionality, and the composite score was calculated by adding all the scores from 14 items (Cronbach's $\alpha=.93$ ).

Positive family environment. We assessed positive family environment using two measures: family support and family functioning. Familial support and family functioning scores were significantly and positively correlated $(r=.73, p<.001)$; hence, the $\mathrm{z}$-scores for the two measures were averaged to compute the "positive family environment" variable.

The level of support the participant with disability perceived to receive from his/her family was assessed with the Family subscale of the Perceived Social Support Scale (PSS-Fa; Procidano \& Heller, 1983). The Family subscale has 20 items (e.g., $M y$ family gives me the moral support I need) with two response alternatives: Yes (1) and No (0). The total score was composed by adding all the scores on each item (Cronbach's $\alpha=.91$ ).

The level of functioning in the family was assessed with the Family Assessment Device (FAD; Epstein, Baldwin, \& Bishop, 1983). The FAD examines an individual's view of his/her family relations in terms of problem solving, communication, roles, affective responsiveness, affective involvement, behavior control, and general functioning (e.g., In times of crisis we can turn to each other for support). It includes 60 items rated on a 4-point Likert scale (1 = strongly disagree, 4 = strongly agree). Nine items were omitted as they were not applicable to individuals with disabilities (e.g., Family tasks don't get spread around enough). The total family functioning score was calculated by averaging the scores on each item (Cronbach's $\alpha=.93$ ).

Locus of control. The individual's perceived locus of control was measured with the Locus of Control Scale (Dag, 2002), which includes 47 items tapping internal/external locus of control, belief in luck, meaninglessness of striving, fatalism, and belief in an unjust world (e.g., Some people are born lucky). The items are rated on a 5-point Likert scale $(1=$ absolutely inappropriate, 5 = absolutely appropriate), and the locus of control score was calculated by averaging the scores, with higher scores indicating higher levels of external locus of control (Cronbach's $\alpha=.83$ ).

Learned resourcefulness. Individuals with disability completed the Self-Control Scale (SCS; Rosenbaum, 
Table 1

Sociodemographic and clinical characteristics of individuals with orthopedic disability and their family caregivers

\begin{tabular}{|c|c|c|}
\hline & $\begin{array}{c}\text { Individuals with } \\
\text { orthopedic disability } \\
(N=161)\end{array}$ & $\begin{array}{l}\text { Family caregivers } \\
\qquad(N=161)\end{array}$ \\
\hline \multicolumn{3}{|l|}{ Gender } \\
\hline Male & $112(69.56 \%)$ & $44(27.33 \%)$ \\
\hline Female & $49(30.43 \%)$ & $114(70.81 \%)$ \\
\hline Mean age $(S D)$ & $35.60(10.18)$ & $44.07(14.79)$ \\
\hline \multicolumn{3}{|l|}{ Caregiver family relation } \\
\hline Mother & - & $51(31.68 \%)$ \\
\hline Father & - & $12(7.45 \%)$ \\
\hline Spouse & - & $49(30.43 \%)$ \\
\hline Sibling & - & $40(24.84 \%)$ \\
\hline Other (e.g., adult child, niece, aunt) & - & $9(5.59 \%)$ \\
\hline \multicolumn{3}{|l|}{ Marital status } \\
\hline Married & $59(36.65 \%)$ & - \\
\hline Single & $93(57.76 \%)$ & - \\
\hline Separated/Divorced & $9(5.59 \%)$ & - \\
\hline \multicolumn{3}{|l|}{ Education } \\
\hline Illiterate/Did not complete elementary school & $13(8.07 \%)$ & $12(7.45 \%)$ \\
\hline Primary school graduate & $47(29.19 \%)$ & $76(47.20 \%)$ \\
\hline Secondary school graduate & $33(20.50 \%)$ & $24(14.91 \%)$ \\
\hline High school graduate & $57(35.40 \%)$ & $27(16.77 \%)$ \\
\hline University degree & $11(6.83 \%)$ & $14(8.70 \%)$ \\
\hline \multicolumn{3}{|l|}{ Employment status } \\
\hline Unemployed & $97(60.25 \%)$ & $114(70.81 \%)$ \\
\hline Employed part-time & $10(6.21 \%)$ & $33(20.50 \%)$ \\
\hline Employed full-time & $27(16.77 \%)$ & $10(6.21 \%)$ \\
\hline Student & $27(16.77 \%)$ & - \\
\hline Mean age of disability onset ${ }^{*}$, years $(S D)$ & $21.57(12.95)$ & - \\
\hline Mean time since disability, years $(S D)$ & $14.04(12.66)$ & - \\
\hline Wheelchair use & $143(88.82 \%)$ & - \\
\hline \multicolumn{3}{|l|}{ Disability type } \\
\hline Paraplegia & $75(46.58 \%)$ & - \\
\hline Quadriplegia & $25(15.53 \%)$ & - \\
\hline Muscular dysmorphia & $16(9.94 \%)$ & - \\
\hline Other (e.g., amputee, polio, multiple sclerosis) & $45(27.95 \%)$ & - \\
\hline
\end{tabular}

Note. * Onset of orthopedic disability was defined as the time of injury for individuals with paraplegia, quadriplegia, polio or amputation; it was defined as the onset of wheelchair use for individuals with muscular dystrophy or multiple sclerosis; and as the time of birth for individuals with spina bifida. 
Ekin Secinti, Bilge Selcuk, Mehmet Harma
1980) to measure learned resourcefulness. The scale has 36 items that assess previously learned skills and tools when attaining a goal effectively (e.g., When I feel sad, I try to think about good things). The items are rated on a 5-point Likert scale $(1=$ absolutely in appropriate, 5 = absolutely appropriate) and averaged to obtain the learned resourcefulness score. One item (If I were smoking two packs of cigarettes every day, I would require another person's help to quit smoking) was omitted as it was considered not closely relevant for the concept of learned resourcefulness measured in this study (Cronbach's $\alpha=.83$ for 35 items).

Acceptance of disability. To measure the level of psychosocial adjustment to disability in the individuals with orthopedic disability, we used the Adaptation to Disability Scale-Revised (ADS-R; Groomes \& Linkowski, 2007). The ADS-R includes 32 items that evaluate the degree to which people find meaning in their circumstances and maintain positive beliefs about themselves: (e.g., With my disability, all areas of $m y$ life are affected in some major way). The items were rated on a 4-point Likert scale ( 1 = strongly disagree, 4 = strongly agree), and the score was computed by taking the mean of all the items (Cronbach's $\alpha=.93$ ).

Depression. To measure depressive symptoms of the individuals with orthopedic disability and of the family caregiver, the Beck Depression Inventory (BDI; Beck, Ward, Mendelson, Mock, \& Erbaugh, 1961) was used. The BDI includes 21 items which are rated on a 4-point Likert scale ranging from 0 to 3 . The sum of scores can range from 0 to 63 , with higher scores indicating more severe depression (Cronbach's $\alpha=.91$ ).

\section{Measures for the family caregiver}

Depression. To measure depressive symptoms of the family caregiver, the Beck Depression Inventory (BDI; Beck et al., 1961) was administered. The internal consistency value for the BDI rated by the family caregiver was .91.

Social support from family. The level of social support the family caregivers perceived to receive was measured by the Family subscale ( 9 items) of the Multidimensional Scale of Perceived Social Support (MSPSS; Zimet, Dahlem, Zimet, \& Farley, 1988). The items (e.g., I have a family member to lean on in times of trouble) were rated on a 5-point Likert scale $(1=$ absolutely true, $5=$ absolutely false $)$, and averaged to obtain the perceived social support from family score (Cronbach's $\alpha=.87$ ).

Social support from friends. Family caregivers' perceived social support from their friends was measured by the Index of Perceived Social Support (IoPSS; Henderson, Duncan-Jones, McAuley, $\&$ Ritchie, 1978). The questionnaire had 10 items (e.g., I do not have any close friends) rated on a 5-point scale $(1=$ absolutely true, $5=$ absolutely false $)$. The items were averaged to compute the score for support from friends (Cronbach's $\alpha=.85$ ).

Burden of the family caregiver. The level of burden experienced by the family caregivers due to the disability of their family member and their own caregiving was measured with the Burden Assessment Scale (BAS; Reinhard, Gubman, Horwitz, \& Minsky, 1994). The BAS has 19 items (e.g., In the last 6 months did you find it difficult to concentrate on your own activities because of your relative's orthopedic disability?) rated on a 4 -point Likert scale $(1=$ not at all, $4=$ all the time $)$. The scores were averaged to compute the total 'burden of caregiving' score (Cronbach's $\alpha=.88$ ).

Family caregiver's rejection. To measure the family caregiver's rejection, we used the Parental Acceptance-Rejection Questionnaire (PARQ; Rohner $\&$ Rohner, 1980). The questionnaire has 24 items rated on a 4-point Likert scale $(1=$ never, 4 = always $)$ measuring warmth/affection, hostility/aggression, indifference/neglect, and undifferentiated rejection (e.g., When my child misbehaves, I make him/her feel I don't love him/her anymore). The scores on warmth/ affection subscales were reversed, then all the items were averaged so that higher scores represented greater caregiver rejection (Cronbach's $\alpha=.85$ ).

\section{PROCEDURE}

The Adaptation to Disability Scale Revised (ADS-R; Groomes \& Linkowski, 2007) was translated into Turkish by the authors. All the other measures used in this study were previously translated into Turkish and used in research conducted in Turkey with people with disability (SCIM-III: Kesiktas et al., 2011; FAD: Ozgul, Yazicioglu, Peker, Taskaynatan, \& Kalyon, 2003), chronic illness (SCS \& BDI: Baydogan \& Dag, 2008; PSS-Fa: Gunes \& Oner, 2009), family caregivers of the individuals with disability (MSPSS \& IoPSS: Yagmurlu, Yavuz, \& Sen, 2015; BAS: Aydemir, Suculluoglu Dikici, Akdeniz, \& Kalayci, 2012), and with normative samples (PARQ: Anjel, 1993).

The data were collected between January and April 2014, after obtaining the approval of the University Institutional Review Board and written informed consent of all the participants with disability and their family caregivers. The participants were recruited via convenience sampling from two hospitals, three physical therapy and rehabilitation centers, and from various disability support groups through internet advertisements on social media sites. The inclusion criteria were: having orthopedic disability related to mobility at least for 3 months, being older than age 12, and currently living with family. The scales were administered one-on-one to the participants with orthopedic disability (lasting about 60 minutes) and the caregiving family member (lasting about 15 minutes). 


\section{RESULTS}

Descriptive statistics are used to summarize the data (see Table 2 for the descriptive statistics). To examine the associations among the variables, we conducted zero-order correlations (see Table 3 for the correlations).
The reports of the individual with orthopedic disability and the reports of the family caregiver showed significant correlations within themselves and with each other. Specifically, the level of functional independence of participants with disability was associated with their own acceptance of disabil-

Table 2

Descriptive statistics $(N=161)$

\begin{tabular}{|c|c|c|c|c|}
\hline Variable & M & $S D$ & $\min$ & $\max$ \\
\hline \multicolumn{5}{|l|}{ Reports of Individual with Orthopedic Disability } \\
\hline Functional independence $(0-75)$ & 44.04 & 15.89 & 10.00 & 75.00 \\
\hline Acceptance of disability (1-4) & 3.07 & 0.58 & 1.41 & 3.97 \\
\hline Positive family environment & 0.00 & 0.93 & -2.86 & 1.10 \\
\hline Perceived family support $(0-1)$ & 0.77 & 0.25 & 0.00 & 1.00 \\
\hline Family strength (1-4) & 3.12 & 0.51 & 1.72 & 3.85 \\
\hline Locus of Control (1-5) & 2.91 & 0.52 & 1.47 & 3.95 \\
\hline Learned Resourcefulness (1-5) & 3.49 & 0.52 & 2.14 & 4.77 \\
\hline Depression (0-63) & 11.69 & 10.40 & 0.00 & 50.00 \\
\hline \multicolumn{5}{|l|}{ Reports of Family Caregiver } \\
\hline Family caregiver's perceived family support (1-5) & 3.97 & 0.96 & 1.00 & 5.00 \\
\hline Family caregiver's perceived friend support (1-5) & 3.39 & 0.91 & 1.00 & 5.00 \\
\hline Family caregiver's depression (0-63) & 11.99 & 10.40 & 0.00 & 44.00 \\
\hline Burden of caregiving (1-4) & 2.02 & 0.62 & 1.00 & 3.68 \\
\hline Family caregiver's rejection (1-4) & 1.37 & 0.37 & 1.00 & 2.60 \\
\hline
\end{tabular}

Table 3

Zero order correlations between study variables $(N=161)$

\begin{tabular}{|c|c|c|c|c|c|c|c|c|c|c|}
\hline & 1 & 2 & 3 & 4 & 5 & 6 & 7 & 8 & 9 & 10 \\
\hline 1. Functional independence & - & & & & & & & & & \\
\hline 2. Acceptance of disability & $.22^{* *}$ & - & & & & & & & & \\
\hline 3. Locus of control & -.16 & $-.45^{* * *}$ & - & & & & & & & \\
\hline 4. Learned resourcefulness & .10 & $.38^{* * *}$ & $-.20^{*}$ & - & & & & & & \\
\hline 5. Depression & -.12 & $-.64^{* * *}$ & $.33^{* * *}$ & $-.49^{* * *}$ & - & & & & & \\
\hline $\begin{array}{l}\text { 6. Positive family environ- } \\
\text { ment }\end{array}$ & .03 & $.37^{* * *}$ & $-.18^{*}$ & $.43^{* * *}$ & $-.44^{* * *}$ & - & & & & \\
\hline $\begin{array}{l}\text { 7. Family caregiver's per- } \\
\text { ceived family support }\end{array}$ & -.01 & .08 & -.06 & .14 & -.07 & $.17^{*}$ & - & & & \\
\hline $\begin{array}{l}\text { 8. Family caregiver's per- } \\
\text { ceived friend support }\end{array}$ & .14 & $.31^{* * *}$ & $-.22^{* *}$ & $.25^{* *}$ & $.24^{* *}$ & $.27^{* *}$ & $.27^{* * *}$ & - & & \\
\hline 9. Family caregiver's depression & -.08 & $-.25^{* *}$ & $.19^{*}$ & -.10 & $.21^{* *}$ & -.09 & $-.45^{* * *}$ & $*-.45^{* * *}$ & - & \\
\hline 10. Burden of caregiving & $-.20^{*}$ & $-.34^{* * *}$ & .15 & $-.29 * * *$ & $.27^{* *}$ & -.09 & $-.18^{*}$ & $-.29^{* * *}$ & $.47^{* * *}$ & - \\
\hline $\begin{array}{l}\text { 11. Family caregiver's rejec- } \\
\text { tion }\end{array}$ & .02 & -.15 & .12 & $-.25^{* *}$ & $.21^{* *}$ & $-.35^{* * *}$ & $*-.26^{* *}$ & -.14 & $.24^{* *}$ & $.24^{* *}$ \\
\hline
\end{tabular}

Depressive feelings in orthopedic disability 
ity and locus of control. Acceptance of disability of individuals with orthopedic disability was negatively correlated with their locus of control and depressive feelings, and positively associated with learned resourcefulness. Locus of control was negatively related to learned resourcefulness and positively correlated with depression. Learned resourcefulness was negatively associated with depression.

The family caregiver's perceived family support was negatively correlated with their own depression, burden of caregiving, and family caregiver rejection, and positively correlated with perceived friend support. Higher friend support was associated with lower levels of family caregiver depression and burden of caregiving, and a more positive family environment (see Table 3).

\section{THE HYPOTHESIZED MODEL}

We tested our hypothesized model using Mplus 6.12, using the maximum likelihood estimation for parameters, and the bias-corrected bootstrapping method, which is recommended when testing mediation with samples smaller than 400 (McCartney, Burchinal, \& Bub, 2006).

In the model, we proposed that distal factors (i.e., caregiver's depression, caregiver's perceived family and friend support, family caregiver's rejection) would be indirectly associated with the depressive feelings of individuals with orthopedic disability via proximal factors such as positive family environment and acceptance of disability (see Figure 1). We also proposed that personal characteristics of individuals with disability (i.e., level of functionality, locus of control, and learned resourcefulness) would have an indirect association with their depressive feelings via acceptance of disability (see Figure 1).

The results of path analysis showed that the fit of the model was acceptable, $\chi^{2}(30, N=161)=53.17$, $p=.006, C F I=.93, R M S E A=.07(90 \% \mathrm{CI}=.04-.10)$, $S R M R=.09$. As can be seen in Figure 1, functional independence of the individual with disability predicted the burden of caregiving, but its role in the acceptance of disability was not significant $(p=.127)$. The burden of the caregiver was predicted by support from friends but not support from family. On the other hand, support from family and support from friends significantly predicted the caregiver's depression, and burden of caregiving was significantly related to caregivers' feelings of depression. Caregiver rejection was predicted by caregiver depression, and a positive family environment was negatively predicted by caregiver rejection. Positive family environment predicted increased rate of acceptance of disability, which in turn predicted lower levels of depression of the person with disability. Acceptance of disability was also predicted by burden of caregiving, internal locus of control, and marginally by learned resourcefulness ( $p=.061)$. Moreover, increased learned resourcefulness, positive family environment, and a higher acceptance rate of disability predicted lessened depressive feelings in the participants with disability.

To examine the indirect effect sizes, we drew 2,000 samples to estimate the bias-corrected bootstrap standard errors and to obtain CIs for the estimates.

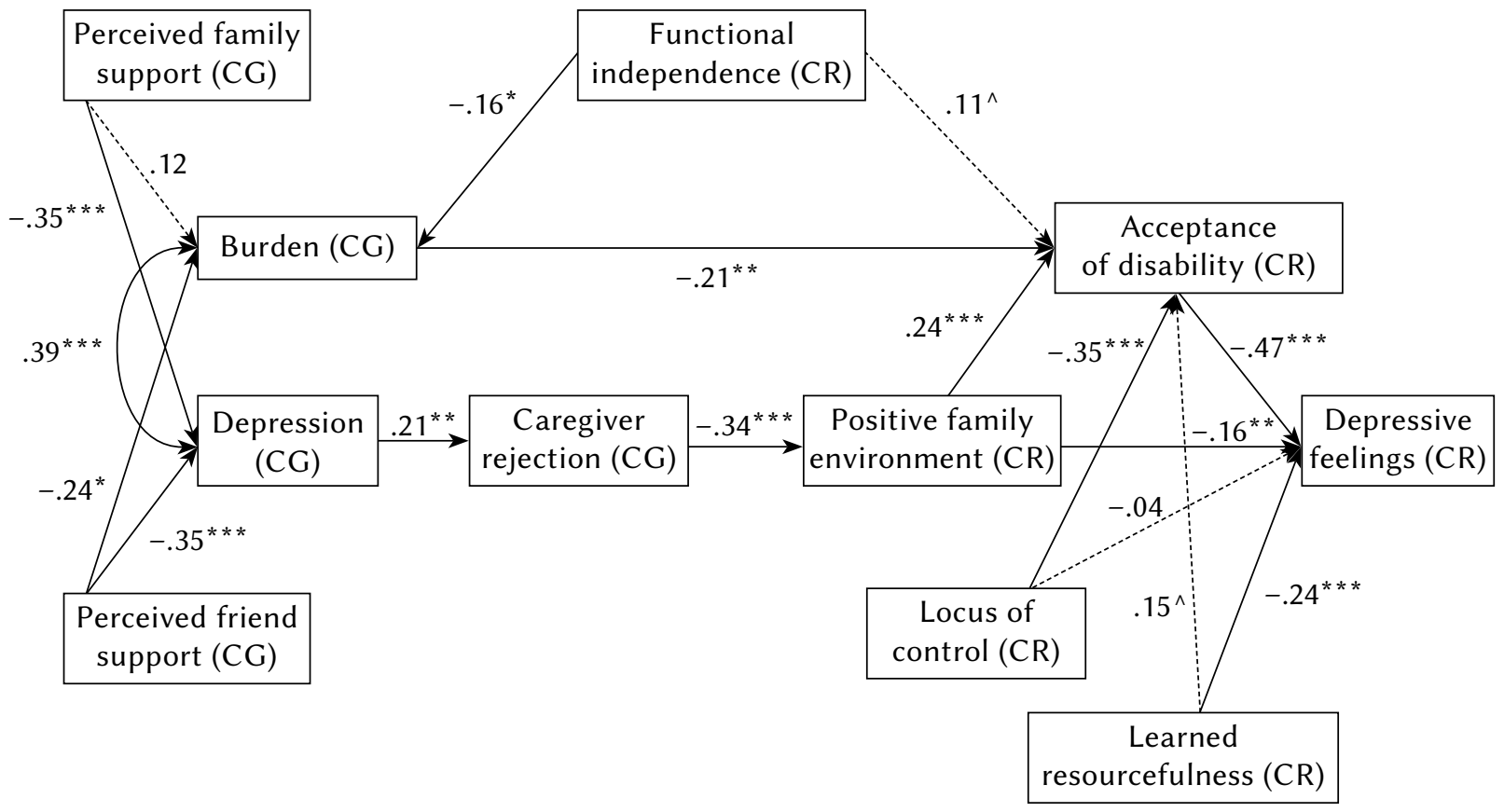

Note. ${ }^{\wedge} p=.06,{ }^{*} p<.05,{ }^{* *} p<.01,{ }^{* *} p<.001$; CG - Caregiver reports, CR - Care-recipient reports

Figure 1. The hypothesized model predicting depressive feelings of persons with disability. 
The results indicated that the link between burden of caregiving and depression was mediated via acceptance of disability, $95 \% \mathrm{CI}=.02$ to .18 . The link between locus of control and depression $(95 \% \mathrm{CI}=.09$ to .24) was also mediated by acceptance of disability.

Caregiver's depression mediated both the path from the family caregiver's perceived family support to rejection $(95 \% \mathrm{CI}=-.14$ to -.01$)$ and the path from the family caregiver's perceived friend support to rejection $(95 \% \mathrm{CI}=-.13$ to -.02$)$.

\section{DISCUSSION}

Multiple factors, including the functional independence of the person, his/her learned resourcefulness and locus of control, and the family environment, might have a role in the depressive feelings of individuals with orthopedic disability. The findings of the present study showed that personal and familial factors were significantly related to depressive feelings in people with orthopedic disability. Only the functional independence of the individuals with orthopedic disability did not predict their depressive feelings, indicating that level of physical limitations is not necessarily associated with elevated feelings of depression among people with disabilities. On the other hand, the depressive feelings and coping resources (e.g., social support) of family caregivers were related to the depressive feelings of people with orthopedic disability and their acceptance of the disability.

Acceptance of disability and depressive feelings of people with orthopedic disability were closely associated with their own learned resourcefulness. People who had a better ability to cope with problems in general also dealt better with their disability and experienced less depression, maybe because they found better ways to deal with the barriers attached to their conditions. Consistent with previous findings (e.g., van Leeuwen et al., 2012), people with orthopedic disability who had an internal sense of control displayed greater acceptance of their physical conditions and experienced fewer depressive tendencies, suggesting that an internal locus of control is a resource that helps persons with disability accept their physical limitations as less devaluing aspects of themselves and embrace their condition, and that it protects them from having significant depressive feelings.

Nevertheless, familial factors were instrumental in understanding the relations between caregivers' and care recipients' depressive feelings. Individuals coming from a more supportive family had greater acceptance of their physical condition, where their family caregivers also had a more caring and helpful friend network, allowing them to feel less depressed and burdened by their caregiving roles.

Among many factors examined, the depressive feelings of the person with disability were related to the burden of caregiving experienced by the family caregiver and the affected individuals' acceptance of the disability. In other words, the caregiver's attitude towards the care recipient was related to how the individual with disability thinks about his/her condition. When family members feel they are pressured and under more responsibility due to their caregiving duties, their attitude towards the individuals with disability might reflect their feelings of burden. Also, based on their caregivers' attitudes, persons with disability might refer to themselves as a burden on their families. This way of thinking might result in difficulty accepting oneself as an able individual, lower adaptation to one's physical condition and, ultimately, to depression.

Caregivers' feelings of burden were related to their increased depression, but this was lower when the caregivers received support from their friends. In line with previous studies (Kim, 2011) on parent-child relations, depression of caregivers predicted hostility, neglect and rejection towards their care recipients with orthopedic disability. The hostile attitude and lack of warmth towards the family member with orthopedic disability in turn predicted a disrupted family environment; the nature of family relations had a role in the way in which the person with disability thought of him/herself - as a burden to the family or, alternatively, as an active member of the family with disability. This problematic, devalued understanding of self was highly predictive of depression among people with disability. Even when we controlled for functional independence, caregiver burden was linked significantly with the individual's acceptance of his/ her physical condition and depressive feelings. This finding suggests that no matter how severe the functional limitations of individuals with disability, when caregivers are warm and affectionate, and hold positive attitudes towards the care recipients, the affected individuals have fewer depressive feelings. This, in turn, is in line with previous research which revealed that people who embrace their orthopedic disability to a greater extent have a more positive family environment, harmonious relations (Jiao et al., 2012), and less depression (Attawong \& Kovindha, 2005).

The results of this study provide important information about the links between personal and familial factors and depressive feelings of Turkish people with disability. However, we must acknowledge that due to the cross-sectional nature of our data, no causal inferences can be drawn from the findings. It must also be noted that although our participants had different types of orthopedic disabilities, the effects of functional independence to outcome variables were negligible. Despite these limitations, our results suggest that loving and caring relationships in the family environment are closely linked to the adaptation of individuals with orthopedic disability to their condition and depressive feelings, while the burden of family
Depressive feelings in orthopedic disability 
Ekin Secinti, Bilge Selcuk, Mehmet Harma caregivers and their negative attitudes disrupt family harmony over and above the severity of the family member's disability. These findings give some clues to the mechanisms through which the well-being of people with orthopedic disability might be alleviated.

Our findings have practical implications for psychosocial interventions for the rehabilitation of people with orthopedic disability. Training programs focusing on the individuals' resourcefulness and mechanisms of self-control, as well as family functioning, are promising ways to promote psychological well-being. Previous studies have shown that activities that increase self-esteem (Yagmurlu, Yagmurlu, \& Yilmaz, 2009) and interventions targeting coping-effectiveness for both the affected individuals (e.g., Kennedy, Duff, Evans, \& Beedie, 2003) and their families (e.g., Rodgers et al., 2007) contribute significantly to improvements in their problem-solving skills, adjustment to disability, and lowering depressive feelings, while also promoting family harmony. Our results suggest that interventions which promote the resources of the individuals with disability and their caregivers, as well as promoting a positive family environment, may help minimize the depressive feelings of individuals with orthopedic disability.

\section{RefERENCES}

Anjel, M. (1993). The transliteral equivalence, reliability and validity studies of the Parental Acceptance-Rejection Questionnaire (PARQ) Mother-Form: A tool for assessing child abuse. Istanbul: Bogazici University School of Social Sciences.

Attawong, T., \& Kovindha, A. (2005). The influencing factors of acceptance of disability in spinal cord injured patients. Nepal Journal of Neuroscience, 2, 67-70.

Aydemir, O., Suculluoglu Dikici, D., Akdeniz, F., \& Kalayci, F. (2012). Reliability and validity of the Turkish version of the Burden Assessment Scale. Archives of Neuropsychiatry, 49, 276-280. doi: 10.4274/npa.y6179

Baydogan, M., \& Dag, I. (2008). Prediction of depressiveness by locus of control, learned resourcefulness and sociotropy-autonomy in hemodialysis patients. Turkish Journal of Psychiatry, 19, 19-28.

Beck, A. T., Ward, C. H., Mendelson, M., Mock, J., \& Erbaugh, J. (1961). An inventory for measuring depression. Achieves of General Psychiatry, 4, 561-571.

Beedie, A., \& Kennedy, P. (2002). Quality of social support predicts hopelessness and depression post spinal cord injury. Journal of Clinical Psychology in Medical Settings, 9, 227-234. doi: 10.1023/A: 1016003428370

Bellin, M. H., Zabel, T. A., Dicianno, B. E., Levey, E., Garver, K., Linroth, R., \& Braun, P. (2010). Cor- relates of depressive and anxiety symptoms in young adults with spina bifida. Journal of Pediatric Psychology, 35, 778-789. doi: 10.1093/jpepsy/ jsp094

Benassi, V. A., Sweeney, P. D., \& Dufour, C. L. (1988). Is there a relation between locus of control orientation and depression? Journal of Abnormal Psychology, 97, 357-367. doi: 10.1037/0021-843X.97.3.357

Budh, C. N., \& Osteraker, A. L. (2007). Life satisfaction in individuals with a spinal cord injury and pain. Clinical Rehabilitation, 21, 89-96. doi: 10.1177/0269215506070313

Cavallo, S., Feldman, D. E., Swaine, B., \& Meshefedjian, G. (2008). Is parental coping associated with the level of function in children with physical disabilities? Child: Care, Health and Development, 35, 33-40. doi: 10.1111/j.1365-2214.2008.00884.x

Chan, R. C. K., Lee, P. W. H., \& Lieh-Mak, F. (2000). Coping with spinal cord injury: personal and marital adjustment in the Hong Kong Chinese setting. Spinal Cord, 38, 687-696. doi: 10.1023/ A: 1016003428370

Craig, A., Tran, Y., \& Middleton, J. (2009). Psychological morbidity and spinal cord injury: A systematic review. Spinal Cord, 47, 108-114. doi: 10.1038/ sc. 2008.115

Crichlow, R. J., Andres, P. L., Morrison, S. M., Haley, S. M., \& Vrahas, M. S. (2006). Depression in orthopaedic trauma patients, prevalence and severity. Journal of Bone and Joint Surgery, American Volume, 88, 1927-1933. doi: 10.2106/JBJS.D.02604

Dag, I. (2002). Locus of Control Scale: Scale development, reliability and validity study. Turkish Journal of Psychology, 17, 77-90.

DeLongis, A., \& Holzman, S. (2005). Coping in context: The role of stress, social support, and personality in coping. Journal of Personality, 73, 1-24. doi: 10.1111/j.1467-6494.2005.00361.x

DeVivo, M. J., Black, K. J., Richards, J. S., \& Stover, S. L. (1991). Suicide following spinal cord injury. Paraplegia 29, 620-627. doi: 10.1038/sc.1991.91

Donelan, K., Hill, C. A., Hoffman, C., Scoles, K., Hoffman, P. H., Levine, C., \& Gould, D. (2002). Challenged to care: Informal caregivers in a changing spinal cord injury. Health Affairs, 21, 222-231. doi: 10.1377/hlthaff.21.4.222

Dreer, L. E., Elliott, T. R., Shewchuk, R., Berry, J. W., \& Rivera, P. (2007). Family caregivers of persons with spinal cord injury: predicting caregivers at risk for probable depression. Rehabilitation Psychology, 52, 351-357. doi: 10.1037/0090-5550.52.3.351

Drummond-Young, M., LeGris, J., Browne, G., Pallister, R., \& Roberts, J. (1995). Interactional styles of out-patients with poor adjustment to chronic illness receiving problem-solving counselling. Health and Social Care in the Community, 4, 317329. doi: 10.1111/j.1365-2524.1996.tb00078.x 
Elfstrom, M., Kreuter, M., Ryden, A., Persson, L. O., \& Sullivan, M. (2002). Effects of coping on psychological outcome when controlling for background variables: a study of traumatically spinal cord lesioned persons focus on coping. Spinal Cord, 40, 408-415. doi: 10.1080/16501970410034414

Elliott, T. R., \& Berry, J. W. (2009). Brief problem solving training for family caregivers of persons with recent onset spinal cord injuries: a randomized controlled trial. Journal of Clinical Psychology, 65, 406-422. doi: 10.1002/jclp.20527

Elliott, T. R., \& Pezent, G. D. (2008). Family caregivers of older persons in rehabilitation. Neurorehabilitation, 23, 1-8.

Elliott, T. R. (1999). Social problem-solving abilities and adjustment to recent onset spinal cord injury. Rehabilitation Psychology, 44, 315-332. doi: 10.1037/0090-5550.44.4.315

Elliott, T. R., Uswatte, G., Lewis, L., \& Palmatier, A. (2000). Goal instability and adjustment to physical disability. Journal of Counseling Psychology, 47, 251-265. doi: 10.1037/0022-0167.47.2.251

Epstein, N. B., Baldwin, L. M., \& Bishop D. S. (1983). The McMaster Family Assessment Device. Journal of Marital and Family Therapy, 9, 171-180. doi: 10.1111/j.1752-0606.1983.tb01497.x

Fekete, C., Eriks-Hooglans, I., Baumberger, M.,Catz,A., Itzkovich, M., Luthi, H., Post, M. W., von Elm, E., Wyss, A., \& Brinkhof, M. W. (2013). Development and validation of a self-report version of the spinal cord independence measure (SCIM III). Spinal Cord, 40, 40-47. doi: 10.1038/sc.2012.87

Green, B., Pratt, C., \& Grigsby, T. (1984). Self-concept among persons with long-term spinal cord injury. Archives of Physical Medicine and Rehabilitation, 65, 751-754.

Groomes, D. A. G., \& Linkowski, D. C. (2007). Examining the Structure of the Revised Acceptance Disability Scale. Journal of Rehabilitation, 73, 3-9.

Gunes, Z., \& Oner, H. (2009). Relationship between hopelessness and perceived social support from family patients who has chronic illness. Journal of Istanbul University Florence Nightingale School of Nursing, 17, 16-23.

Henderson, S., Duncan-Jones, P., McAuley H., \& Ritchie, K. (1978). The patient's primary group. British Journal of Psychiatry, 132, 74-86.

Huang, C. Y., Guo, S. E., Hung, C. M., Shih, S. L., Lee, L. C., Hung, G. C., \& Huang, S. M. (2010). Learned resourcefulness, quality of life and depressive symptoms for patients with breast cancer. Oncology Nursing Forum, 37, 280-287. doi: 10.1188/10.ONF.E280-E287

Jiao, J., Heyne, M. M., \& Lam, C. S. (2012). Acceptance of disability among Chinese individuals with spinal cord injuries: the effects of social support and depression. Psychology, 3, 775-781. doi: 10.4236/ psyc.2012.329117
Kahan, J., Mitchell, J., Kemp, B., \& Adkins, R. H. (2006). The results of a 6-month treatment for depression on symptoms, life satisfaction, and community activities among individuals aging with a disability. Rehabilitation Psychology, 51, 13-22. doi: 10.1037/0090-5550.51.1.13

Keany, K. C., \& Glueckauf, R. L. (1993). Disability and value change: an overview and reanalysis of acceptance of loss theory. Rehabilitation Psychology, 38, 199-210. doi: 10.1037/h0080297

Kemp, B. J, \& Krause, J. S. (1999). Depression and life satisfaction among people ageing with post-polio and spinal cord injury. Disability and Rehabilitation, 21, 241-249. doi: 10.1080/096382899297666

Kendall, E., \& Buys, N. (1998). An integrated model of psychosocial adjustment following acquired disability. Journal of Rehabilitation, 64, 16-20.

Kennedy, P., Duff, J., Evans, M., \& Beedie, A. (2003). Coping effectiveness training reduces depression and anxiety following traumatic spinal cord injuries. British Journal of Clinical Psychology, 42, 41-52. doi: 10.1348/014466503762842002.

Kesiktas, N., Paker, N., Bugdayci, D., Sencan, S., Karan A., \& Muslumanoglu, L. (2011). Turkish adaptation of Spinal Cord Independence Measure - Version III. International Journal of Rehabilitation Research, 35, 88-91. doi: 10.1097/ MRR.0b013e32834f402d

Kim, E. (2011). Korean American parental depressive symptoms and parental acceptance-rejection and control. Issues in Mental Health Nursing, 32, 114120. doi: 10.3109/01612840.2010.529239

Kishi, Y., \& Robinson, R. G. (1996). Suicidal plans following spinal cord injury. Journal of Neuropsychiatry, 8, 443-445.

Krause, J. S., Sternberg, M., Lottes, S., \& Maides, J. (1997). Mortality after spinal cord injury: an 11year prospective study. Archives of Physical Medicine and Rehabilitation, 78, 815-821. doi: 10.1016/ S0003-9993(97)90193-3

Li, L., \& Moore, D. (1998). Acceptance of disability and its correlates. The Journal of Social Psychology, 138, 13-25. doi: 10.1080/00224549809600349

McCartney, K. K., Burchinal, M. R., \& Bub, K. L. (2006). Best practices in quantitative methods for developmentalists. Monographs of The Society For Research In Child Development, 71, 1-145. doi: 10.1111/j.1540-5834.2006.07103001.x

Melamed, S., Groswasser, Z., \& Stem, M. J. (1992). Acceptance of disability, work involvement and subjective rehabilitation status of traumatic brain-injured (TBI) patients. Brain Injury, 6, 233-243. doi: 10.3109/02699059209029665

Moroni, L., Colangelo, M., Gallì, M., \& Bertolotti, G. (2007). "I would like to give him my life": Results of a psychological support intervention to caregivers of patients undergoing neuromotor rehabilita-
Depressive feelings in orthopedic disability 
tion. Italian Journal of Occupational Medicine and Ergonomics, 29, 5-17.

Müller, R., Peter, C., Cieza, A., \& Geyh, S. (2012). The role of social support and social skills in people with spinal cord injury - A systematic review of the literature. Spinal Cord, 50, 94-106. doi: 10.1038/sc.2011.116

Oh, H., \& Lee, E. O. (2009). Caregiver burden and social support among mothers raising children with developmental disabilities in South Korea.

Ekin Secinti, Bilge Selcuk, Mehmet Harma

\section{International Journal of Disability, 56, 149-167. doi:} 10.1080/10349120902868624
Ozgul, A., Yazicioglu, K., Peker, F., Taskaynatan, M. A., \& Kalyon, T. A. (2003). The study of the familial functions of married paraplegic patients. Turkish Journal of Physical Medicine and Rehabilitation, 49, 3-7.

Pelletier, P. M., Alfano, D. P., \& Fink, M. P. (1994). Social support, locus of control and psychological health in family members following head or spinal cord injury. Applied Neuropsychology, 1, 38-44. doi: 10.1080/09084282.1994.9645329

Pierangelo, R., \& Giuliani, G. (2007). The educator's manual of disabilities and disorders. San Francisco, CA: Wiley.

Post, M. W., \& van Leeuwen, C. M. (2012). Psychosocial issues in spinal cord injury: a review. Spinal Cord, 50, 382-389. doi: 10.1038/sc.2011.182

Procidano, M. E., \& Heller, K. (1983). Measures of perceived social support from friends and from family: Three validation studies. American Journal of Community Psychology, 11, 1-24. doi: 10.1007/ BF00898416

Reinhard, S. C., Gubman, G. D., Horwitz, A. V., \& Minsky, S. (1994). Burden Assessment Scale for families of the seriously mentally ill. Evaluation and Program Planning, 17, 261-269. doi: 10.1016/01497189(94)90004-3

Rintala, D. H., Robinson-Whelen, S., \& Matamoros, R. (2005). Subjective stress in male veterans with spinal cord injury. Journal of Rehabilitation Research and Development, 42, 291-304. doi: 10.1682/ JRRD.2005.10.0155

Robinson-Whelen, S., \& Rintala, D. H. (2003). Informal care providers for veterans with $\mathrm{SCl}$ : who are they and how are they doing? Journal of Rehabilitation Research and Development, 40, 511-516.

Rodgers, M. L., Strode, A. D., Norell, D. M., Short, R. A., Dyck, D. G., \& Becker, B. (2007). Adapting multiple-family group treatment for brain and spinal cord injury intervention development preliminary outcomes. American Journal of Physical Medicine \& Rehabilitation, 86, 482-492. doi: 10.1097/PHM. 0b013e31805c00a1

Rohner, R. P., \& Rohner, E. C. (1980). Worldwide tests of parental acceptance-rejection theory. Behavioral Science Research, 15, 1-21.
Rosenbaum, M. (1990). The role of learned resourcefulness in the self-control of health behavior. In M. Rosenbaum (ed.), Learned resourcefulness On coping skills, self-control, and adaptive behavior (pp. 3-29). New York, NY: Springer.

Rosenbaum, M. (1980). A schedule for assessing self-controlling behaviors: Preliminary findings. Behavior Therapy, 11, 109-121.

Rosenbaum, M., \& Palmon, N. (1984). Helplessness and resourcefulness in coping with epilepsy. Journal of Consulting and Clinical Psychology, 52, 244253. doi: 10.1016/S0005-7894(80)80040-2

Rotter, J. B. (1966). Generalized expectancies for internal versus external control of reinforcement. Psychological Monographs, 80 (1, Whole No. 609). doi: $10.1037 / \mathrm{h} 0092976$

Russell, D., Turner, R. J., \& Joiner, T. E. (2009). Physical disability and suicidal ideation: a community-based study of risk/protective factors for suicidal thoughts. Suicide and Life Threatening Behavior, 39, 440-451. doi: 10.1521/suli.2009.39.4.440

Sav, A., Kendall, E., McMillan, S., Kelly, F., Whitty, J. A., King, M. A., \& Wheeler, A. J. (2013). 'You say treatment, I say hard work': treatment burden among people with chronic illness and their carers in Australia. Health and Social Care in the Community, 21, 665-674. doi: 10.1111/hsc. 12052

Singh, R., Ripley, D., Pentland, B., Todd, I., Hunter, J., Hutton, L., \& Philip, A. (2009). Depression and anxiety symptoms after lower limb amputation: the rise and fall. Clinical Rehabilitation, 23, 281286. doi: $10.1177 / 0269215508094710$

Snead, S. L., \& Davis, J. R. (2002). Attitudes of individuals with acquired brain injury towards disability. Brain Injury, 16, 947-953. doi: 10.1080/02699050210147211

Turkish Statistical Institute (2010). Survey on Problems and Expectations of Disabled People. Retrieved from http://www.tuik.gov.tr

Unalan, H., Gencosmanoglu, B., Akgun, K., Karamehmetoglu, S., Tuna, H., Ones, K., Rahimpenah, A., Uzun, E., \& Tüzün, F. (2001). Quality of life of primary caregivers of spinal cord injury survivors living in the community: Controlled study with short form-36 questionnaire. Spinal Cord, 39, 318322. doi: $10.1038 /$ sj.sc.3101163

Van Leeuwen, C. M., Kraaijeveld, S., Lindeman, E., \& Post, M. W. (2012). Associations between psychological factors and quality of life ratings in persons with spinal cord injury: a systematic review. Spinal Cord, 50, 174-187. doi: 10.1038/sc.2011.120

Vitaliano, P. P., Zhang, J., \& Scanlan, J. (2003). Is caregiving hazardous to one's physical health? A meta-analysis. Psychological Bulletin, 129, 946-972. doi: 10.1037/00332909.129.6.946

Waldron, B., Benson, C., O’Connell, A., Byrne, P., Dooley, B., \& Burke, T. (2010). Health locus of control and attributions of cause and blame in 
adjustment to spinal cord injury. Spinal Cord, 48, 598-602. doi: 10.1038/sc.2009.182

Weitzenkamp, D., Gerhart, K. A., Charlifue, S. W., \& Whiteneck, G. G. (1997). Spouses of spinal cord injured survivors: the added impact of caregiving. Archives of Physical Medicine and Rehabilitation, 78, 822-827. doi: 10.1016/S0003-9993(97)90194-5

Williams, A. M., Wang, L., \& Kitchen, P. (2016). Impacts of care-giving and sources of support: a comparison of end-of-life and non-end-of-life caregivers in Canada. Health \& Social Care in the Community, 24, 214-224. doi: 10.1111/hsc. 12205

Woodrich, F., \& Petterson, J. B. (1983). Variables related to acceptance of disability in persons with spinal cord injuries. Journal of Rehabilitation, 49, 26-30.

Yagmurlu, M. F., Yagmurlu, B., \& Yilmaz, M. (2009). Orthopedic disability and socioemotional functioning. Pediatrics International, 51, 637-644. doi: 10.1111/j.1442-200X.2009.02821.x

Yagmurlu, B., Yavuz, H. M., \& Sen, H. (2015). Well-being of mothers of children with orthopedic disabilities in a disadvantaged context: findings from Turkey. Journal of Child and Family Studies, 24, 948-956. doi: 10.1007/s10826-014-9905-8

Ylven, R., Bjorck-Akesson, E., \& Granlund, M. (2006). Literature review of positive functioning in families with children with a disability. Journal of Policy and Practice in Intellectual Disabilities, 3, 253-270. doi: 10.1111/j.1741-1130.2006.00089.x

Zimet, G. D., Dahlem, N. W., Zimet, S. G., \& Farley, G. K. (1988). The Multidimensional Scale of Perceived Social Support. Journal of Personality Assessment, 52, 30-41. doi: 10.1207/s15327752jpa5201_2 